\title{
Taming Bronsted Acid Reactivity: Nucleophilic Substitutions of Propargylic Alcohols with N-Nucleophiles Mediated by Phosphorus-Based Bronsted Acid Catalysts
}

\author{
Lalita Radtanajiravong, and Silvia Díez-González* \\ Imperial College London, Department of Chemistry, MSRH, Wood Lane, W12 OBZ London, \\ $U K$ \\ Email: s.diez-gonzalez@imperial.ac.uk
}

Supporting Information 

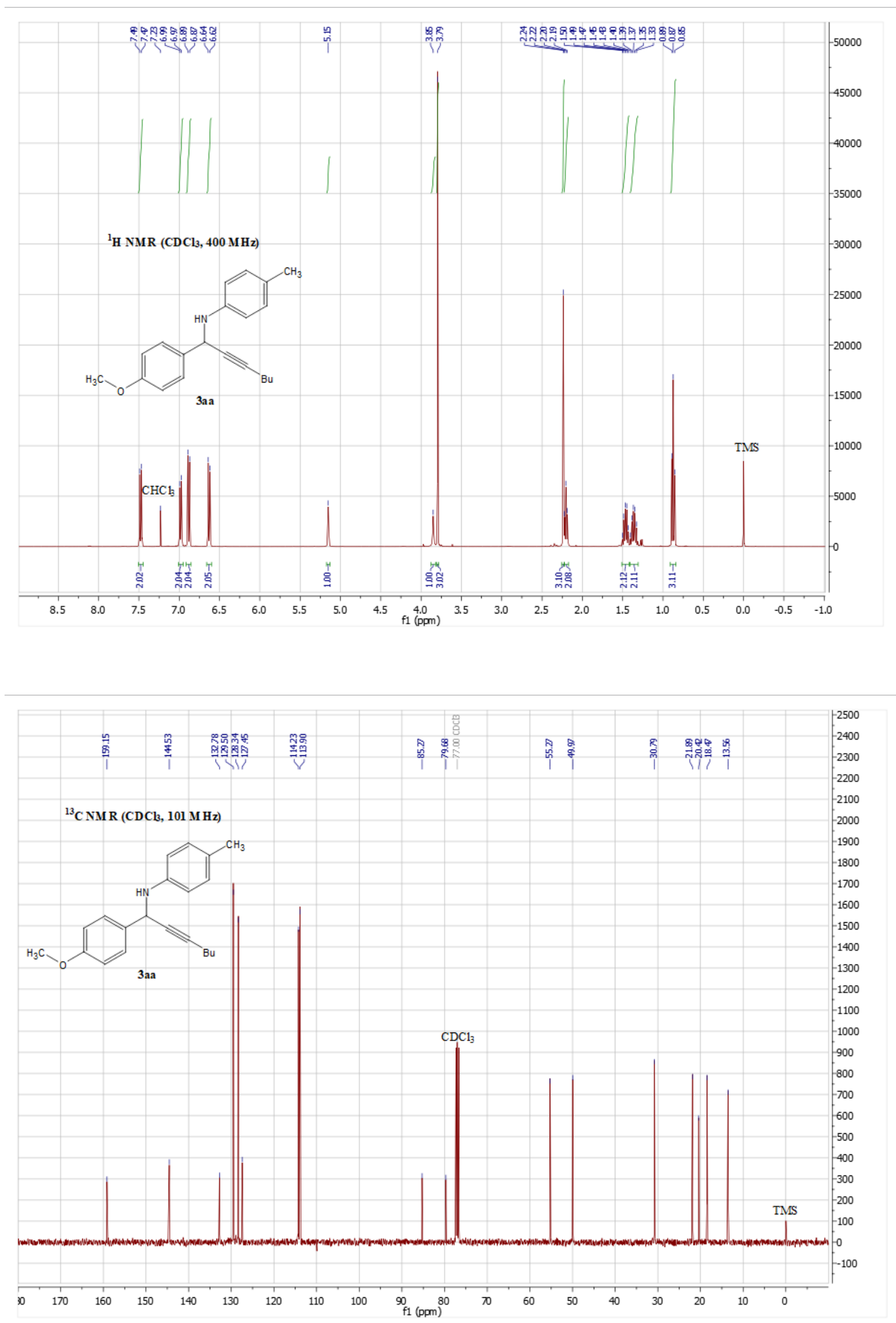

Figure S1. NMR spectra for 3aa 

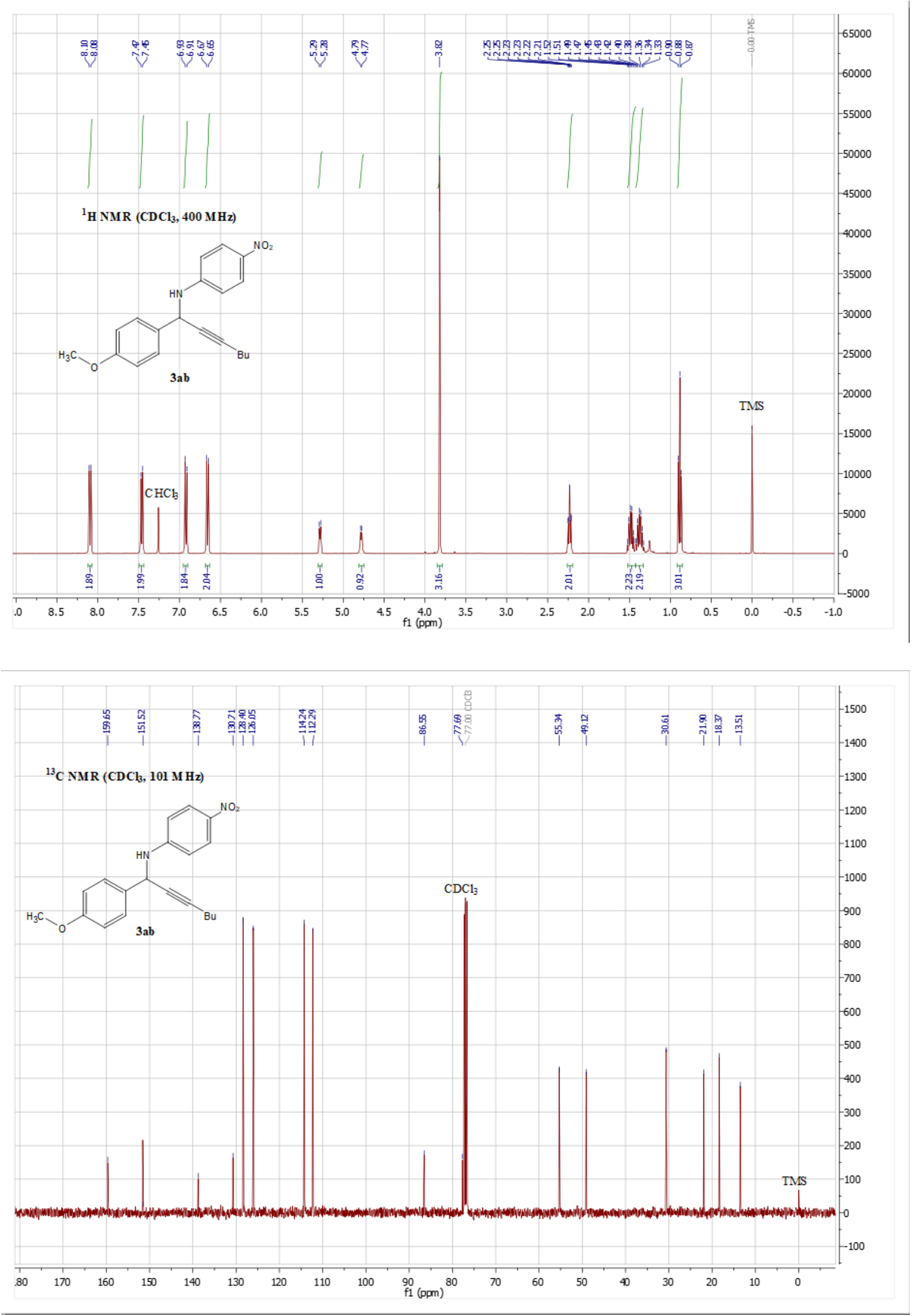

Figure S2. NMR spectra for 3ab 

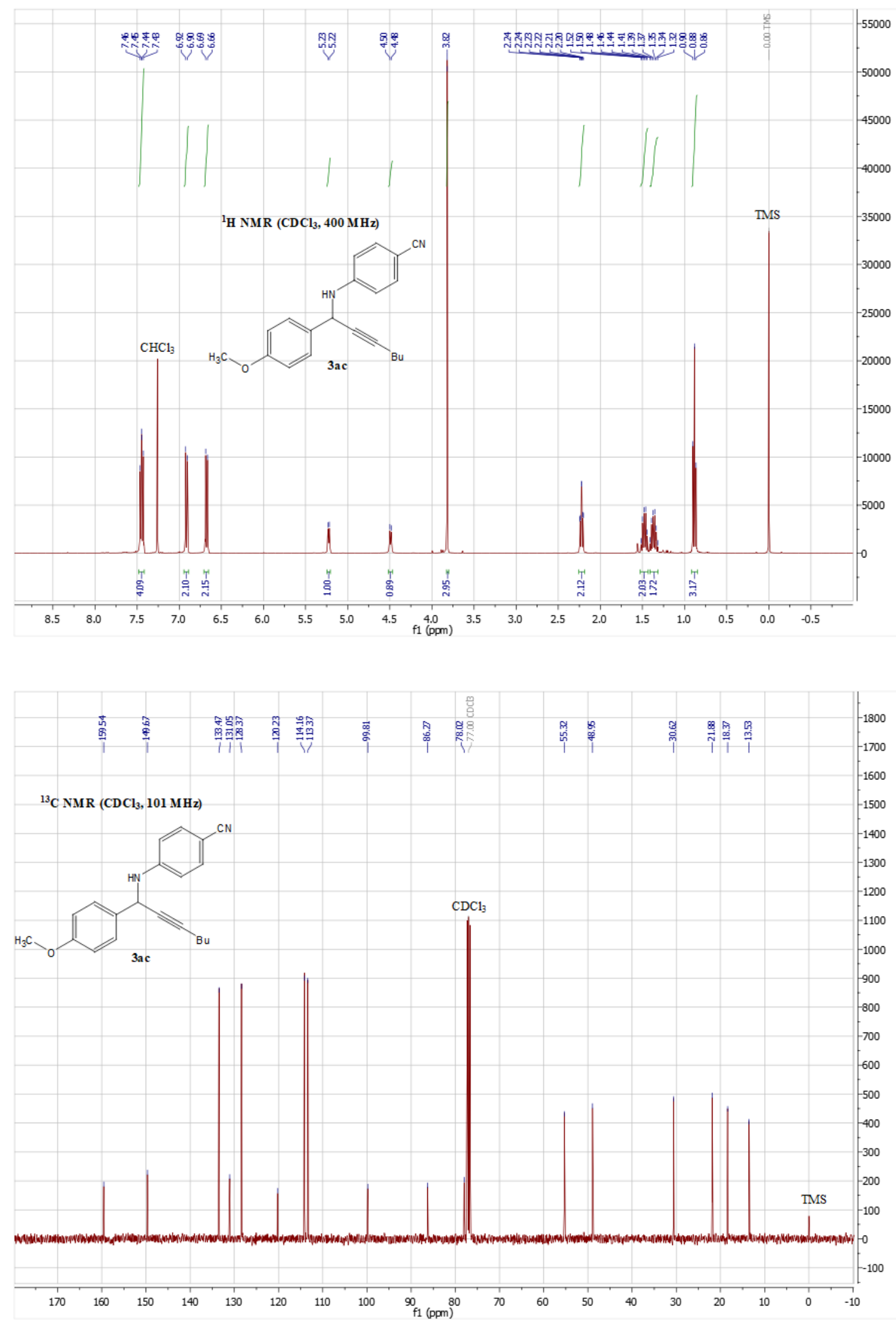

Figure S3. NMR spectra for 3ac 

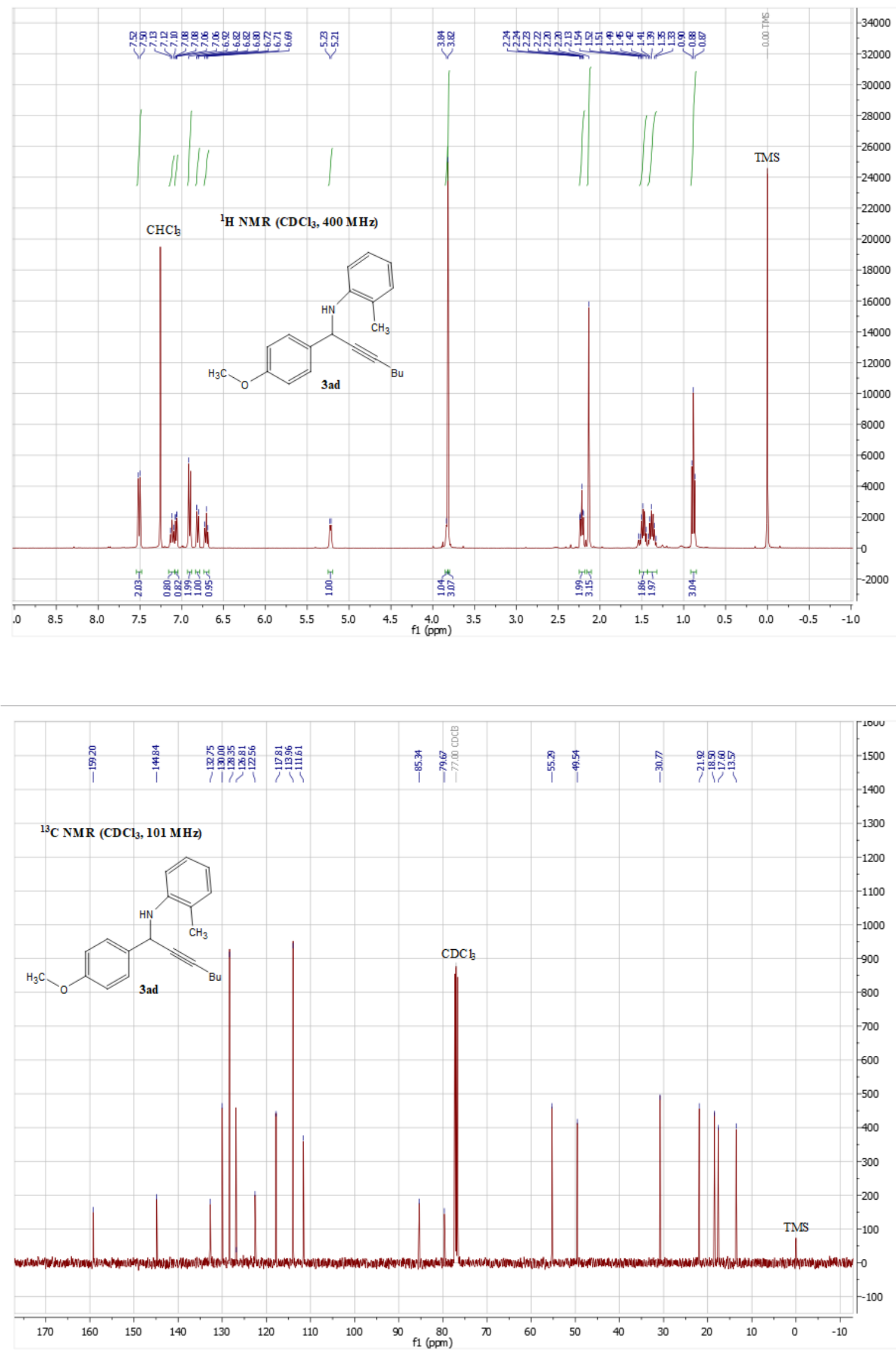

Figure S4. NMR spectra for $\mathbf{3 a d}$ 

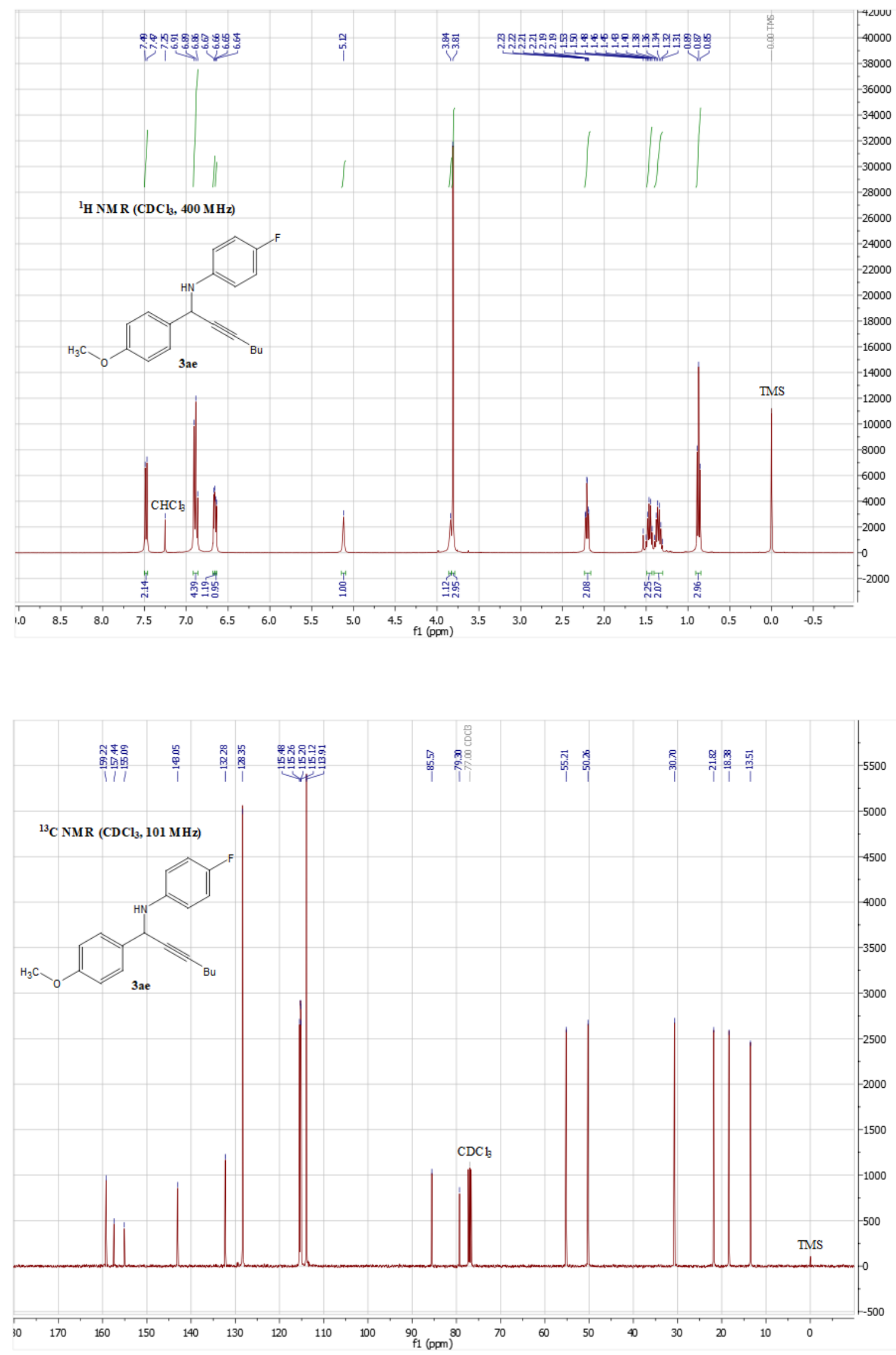

Figure S5. NMR spectra for 3ae 

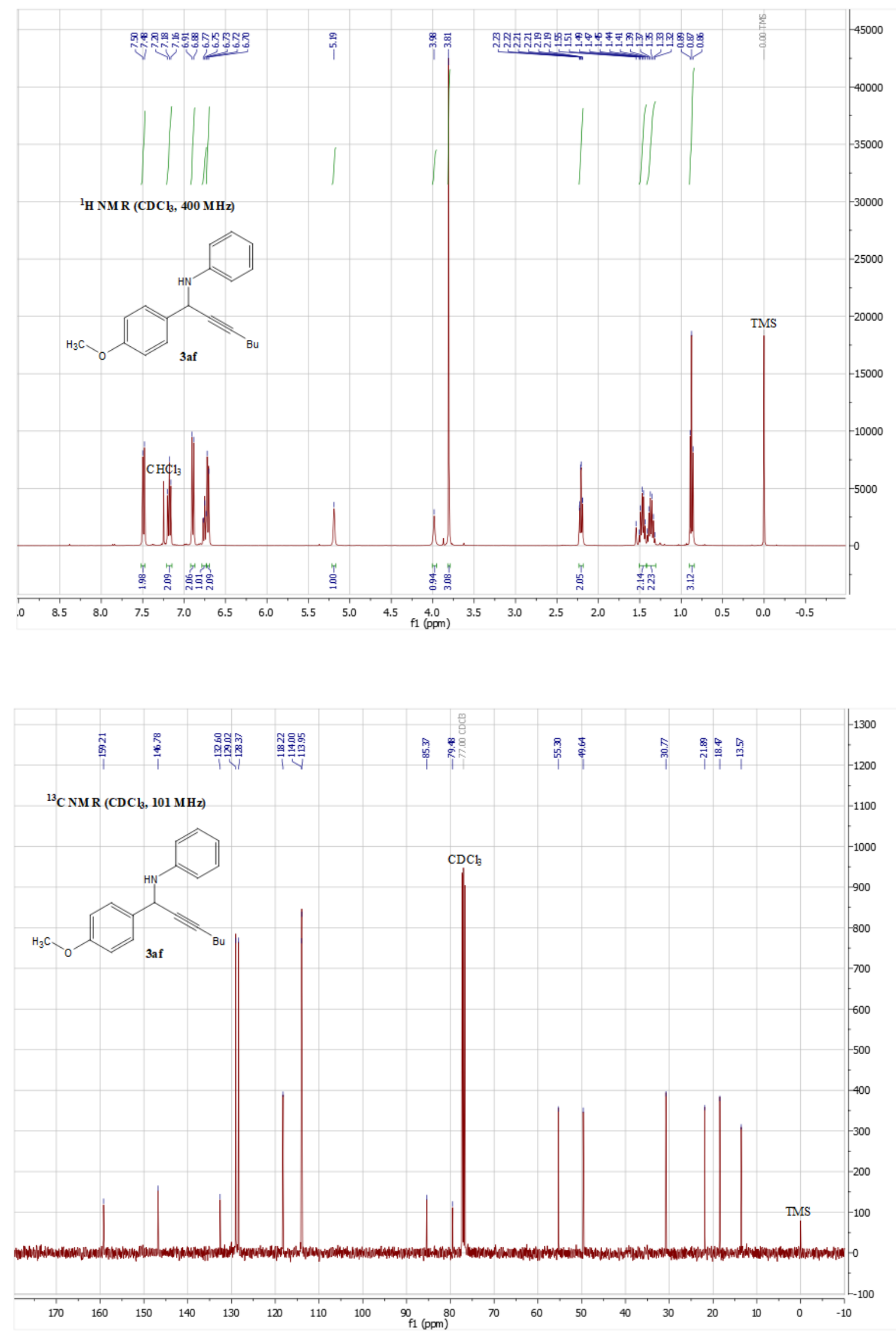

Figure S6. NMR spectra for 3af 

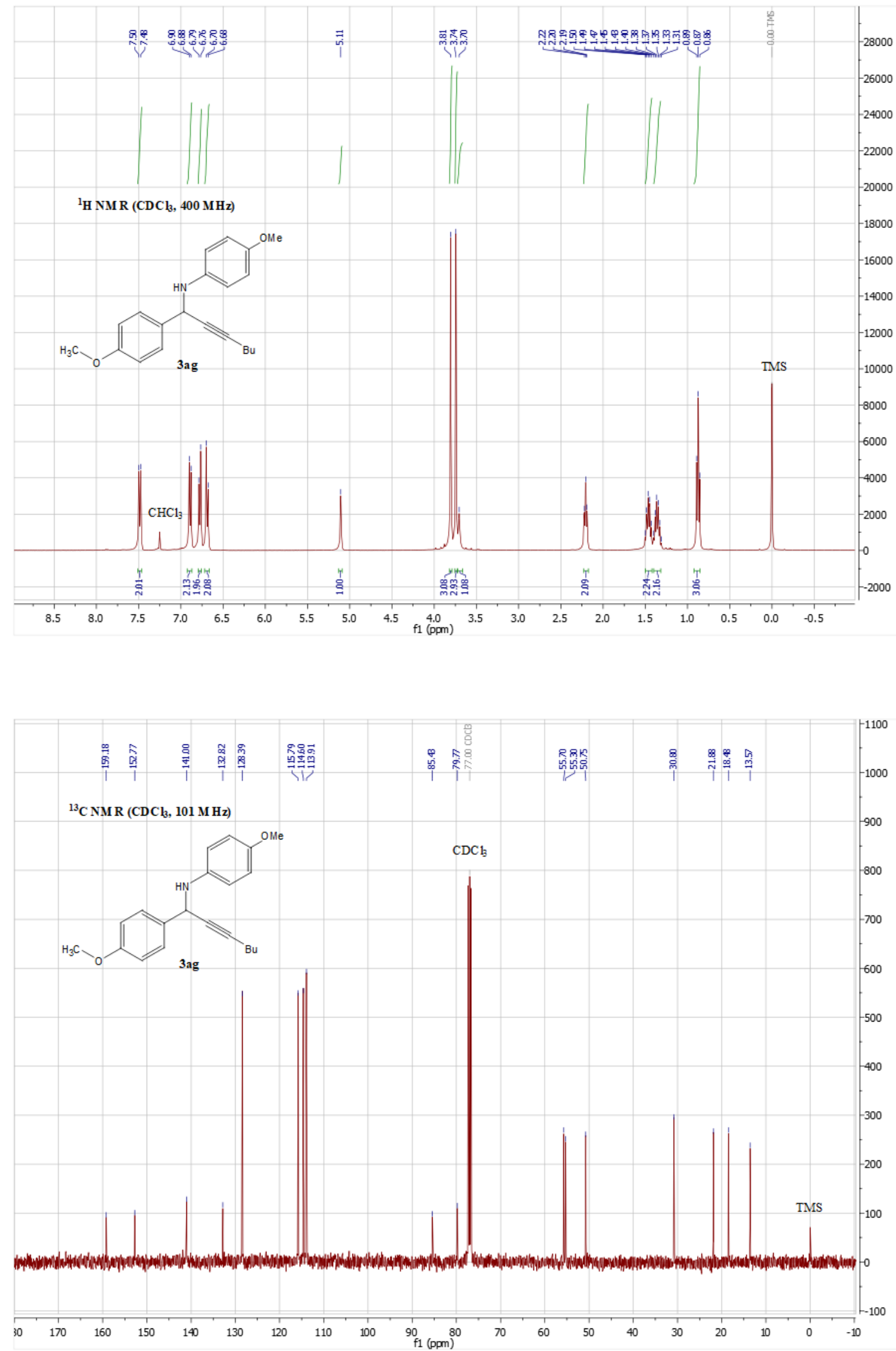

Figure S7. NMR spectra for 3ag 

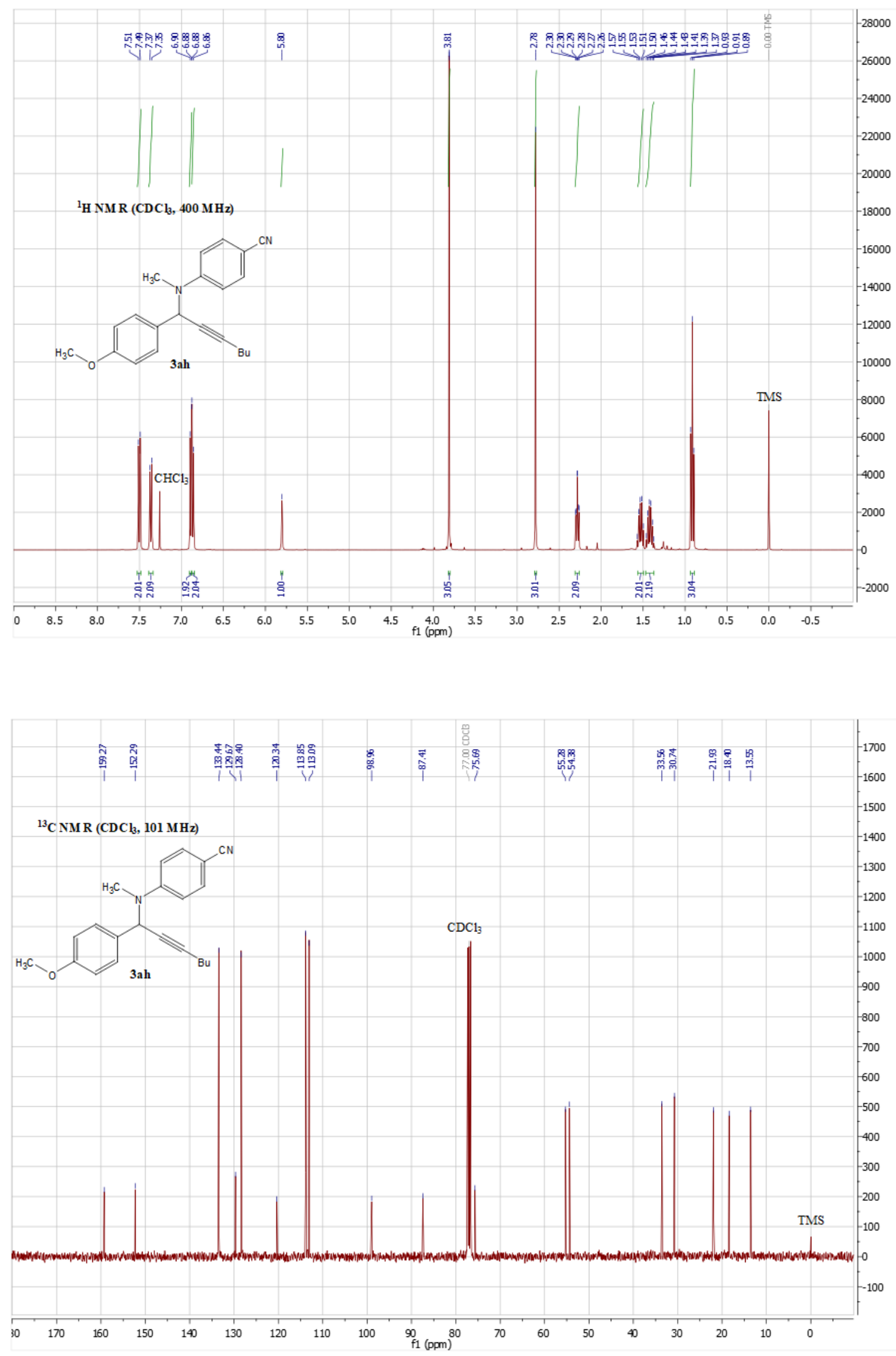

Figure S8. NMR spectra for 3ah 

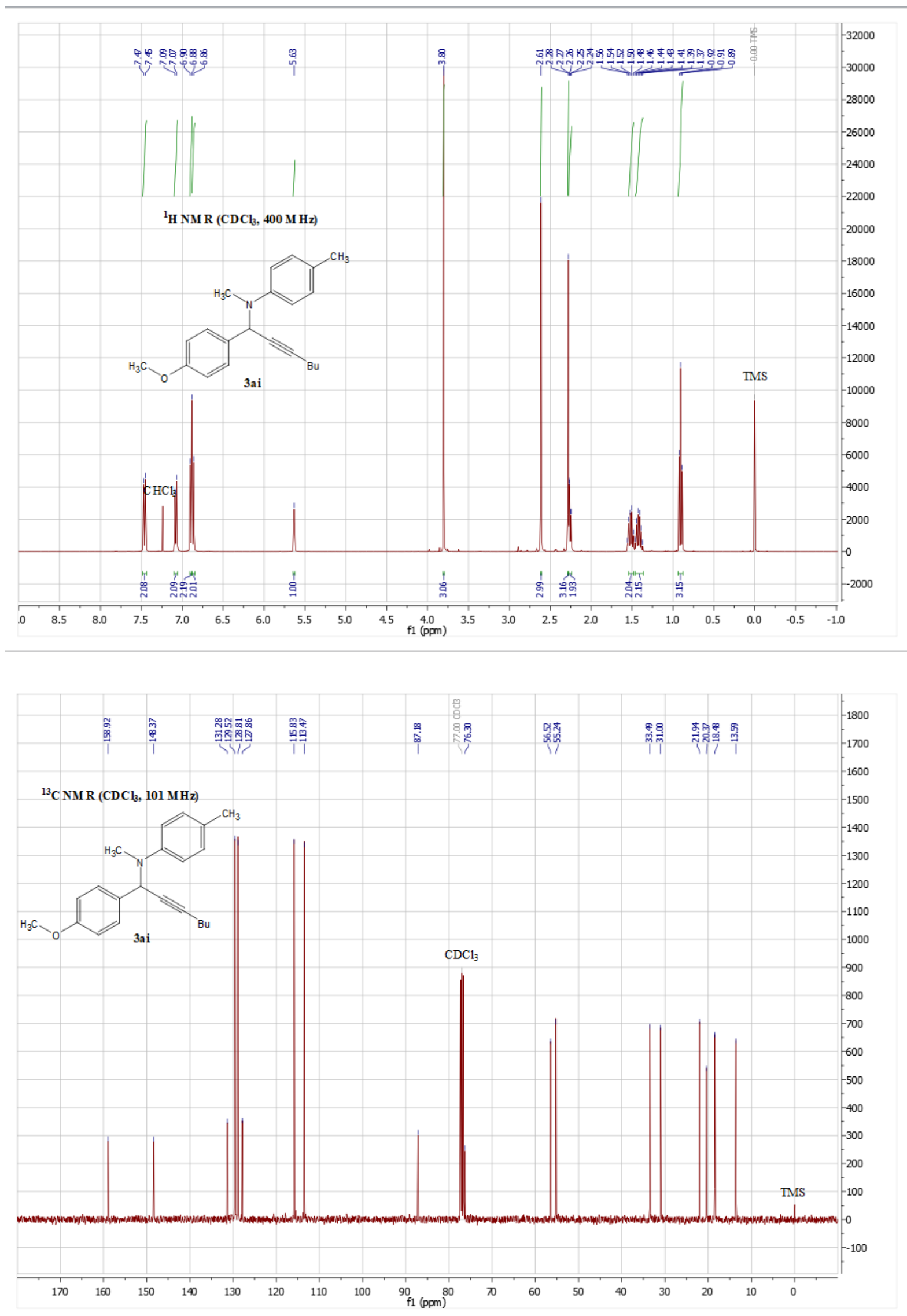

Figure S9. NMR spectra for 3ai 

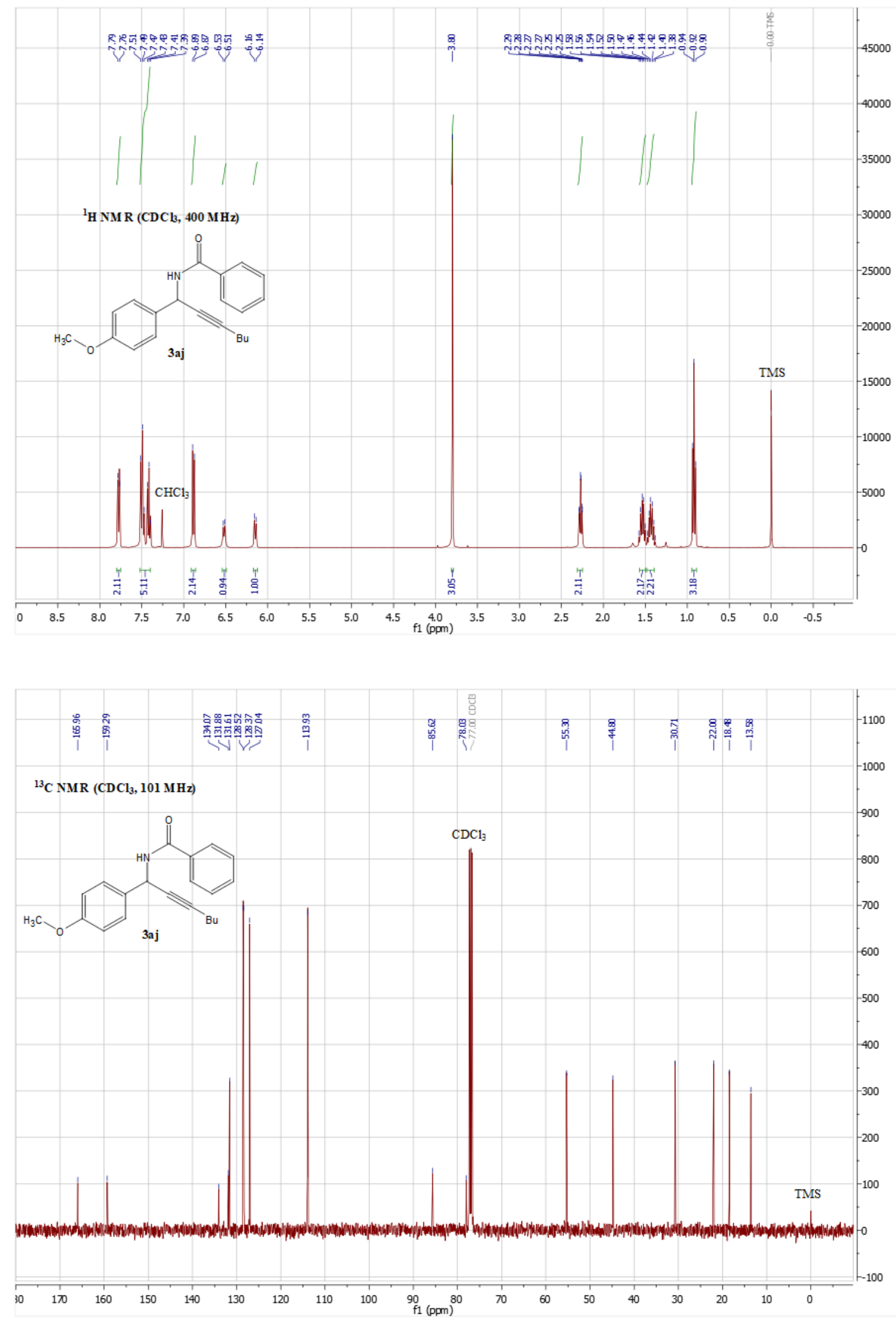

Figure S10. NMR spectra for 3aj 

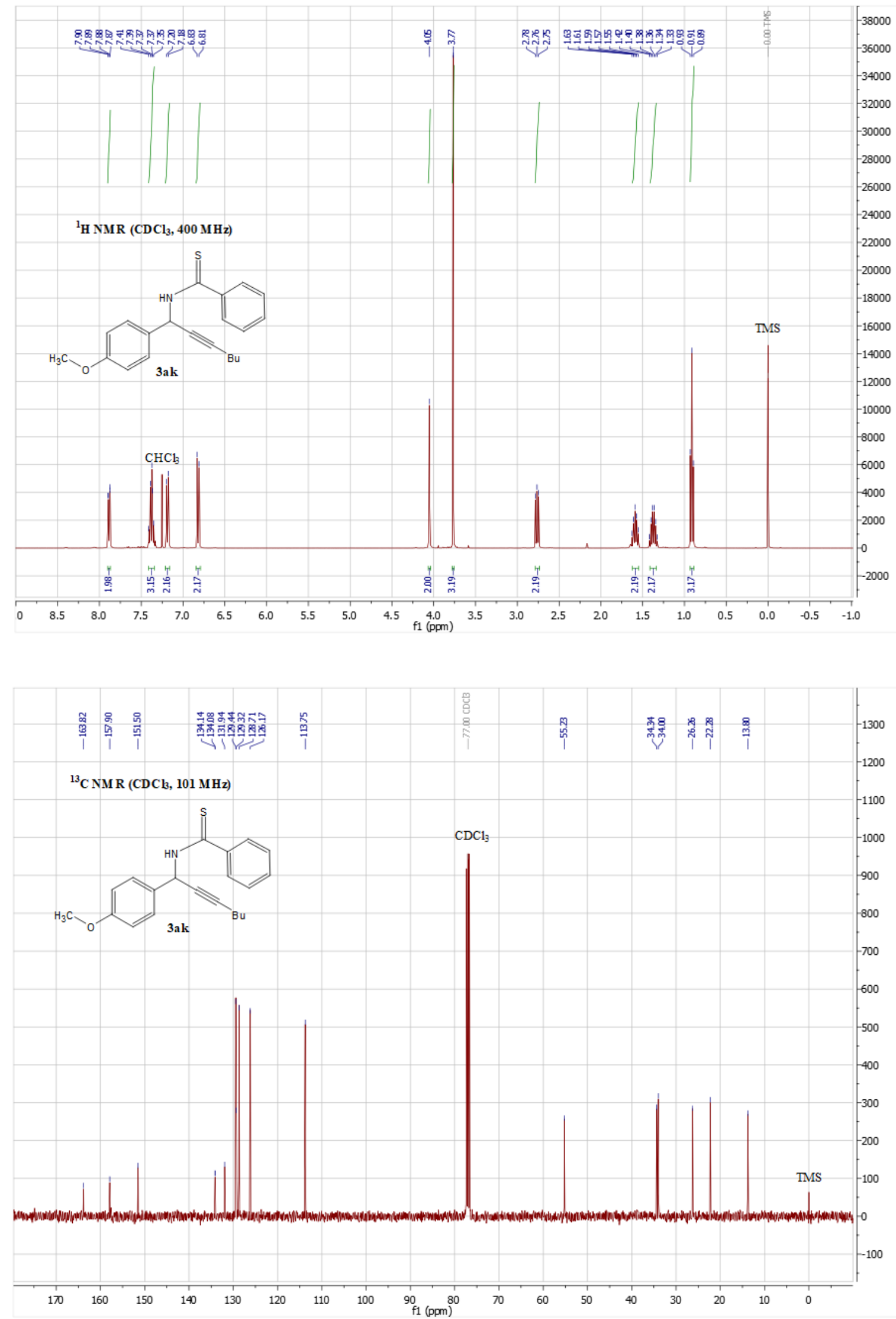

Figure S11. NMR spectra for 3ak 

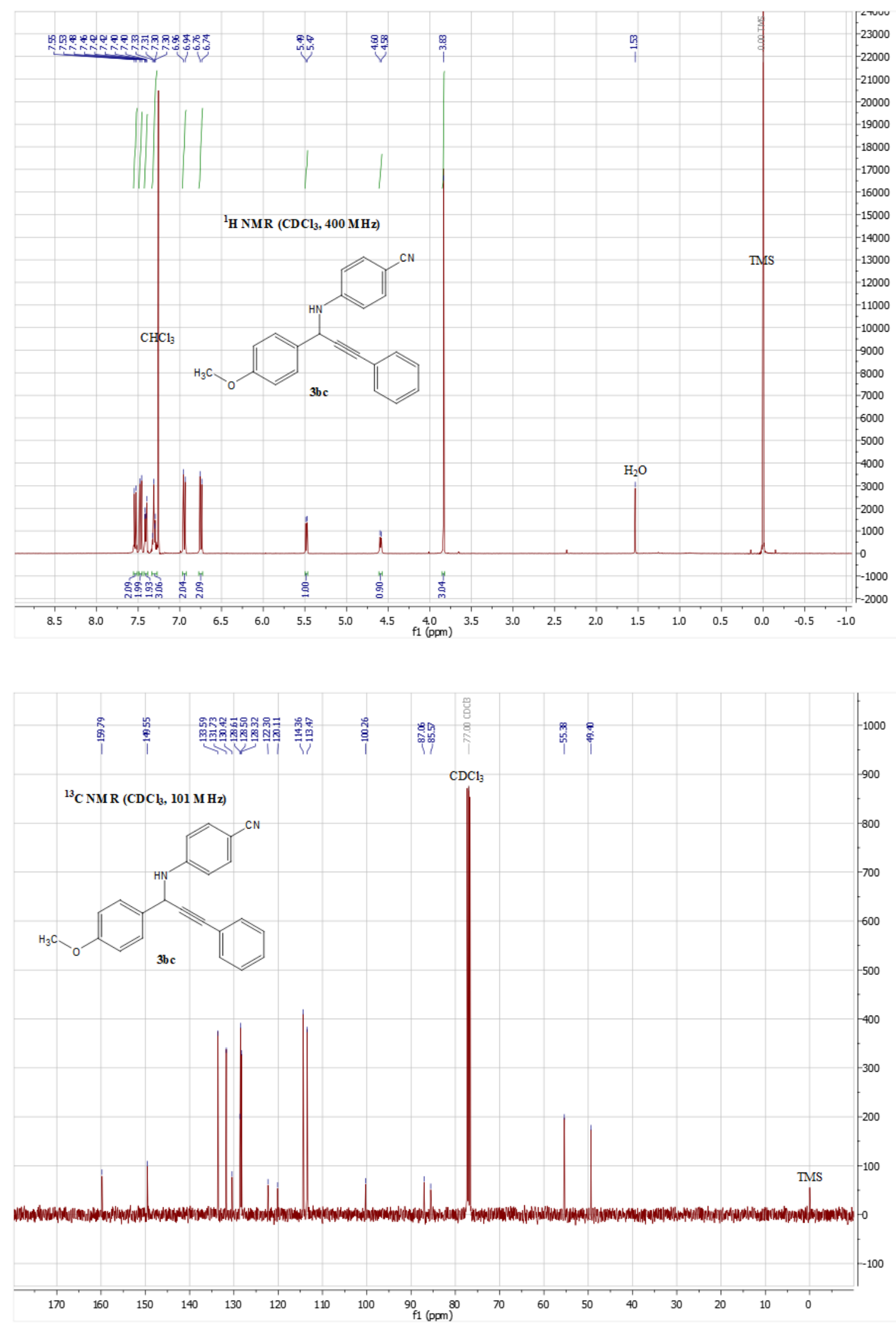

Figure S12. NMR spectra for 3 bc 

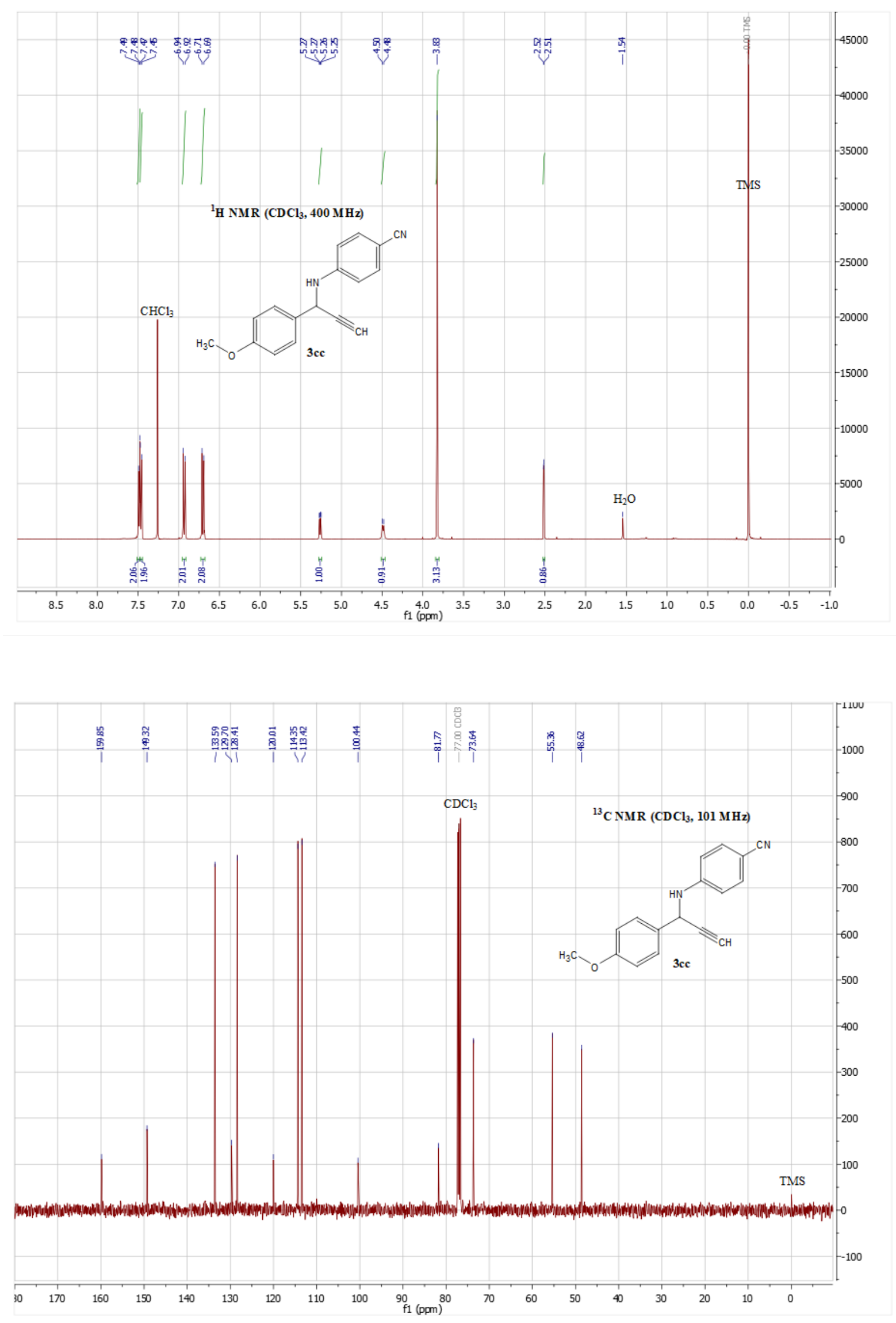

Figure S13. NMR spectra for 3cc 

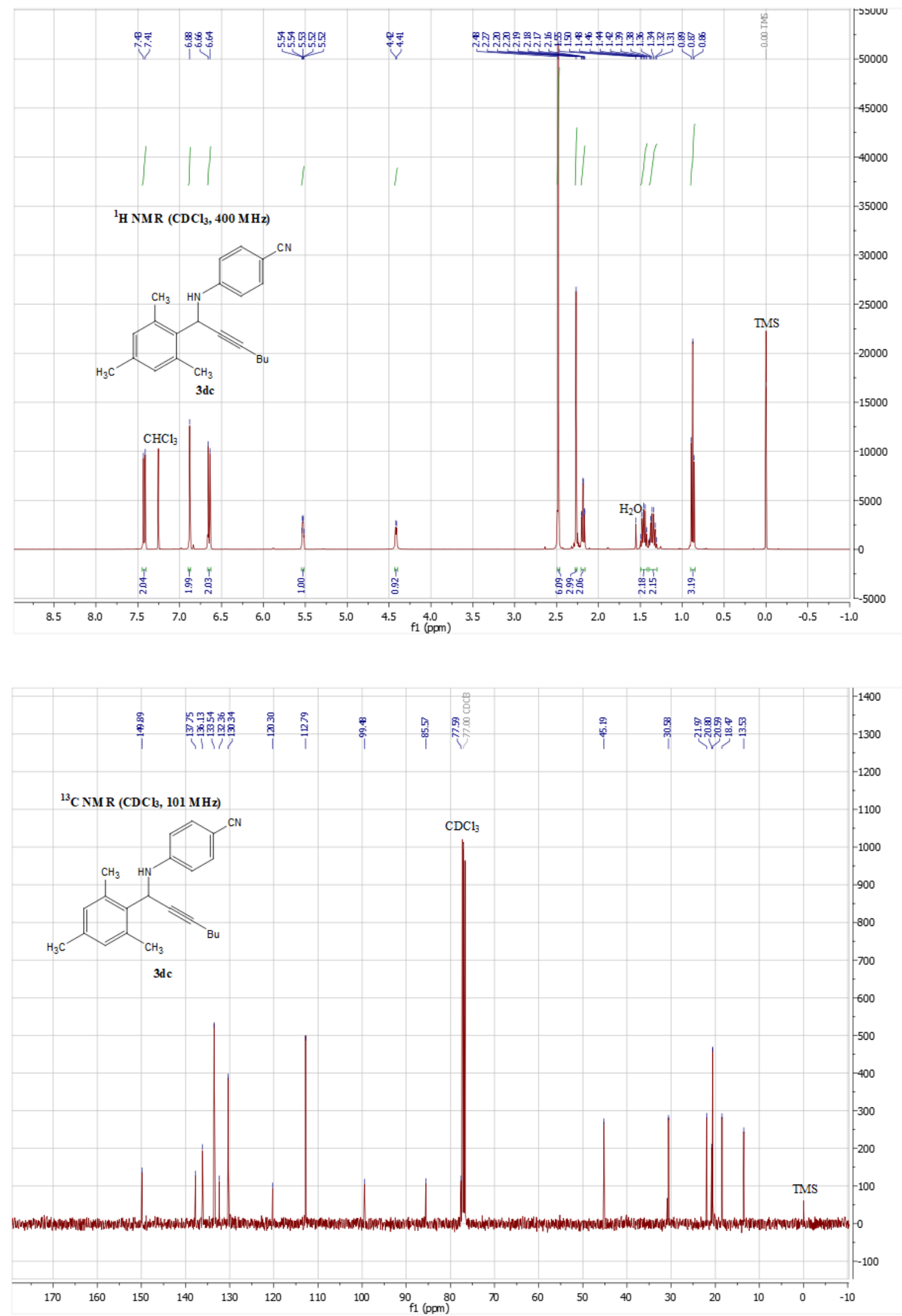

Figure S14. NMR spectra for 3dc 

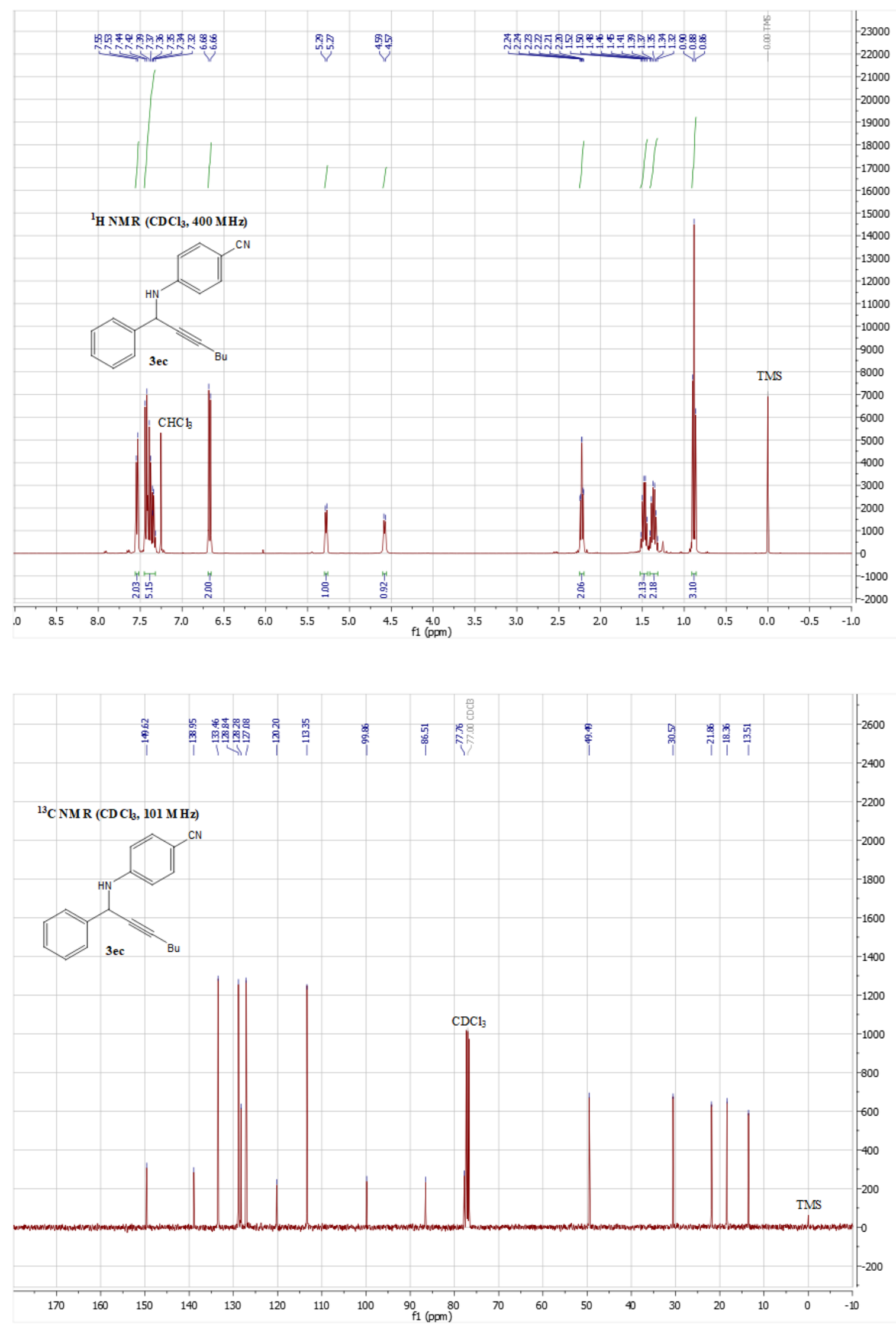

Figure S15. NMR spectra for 3ec 

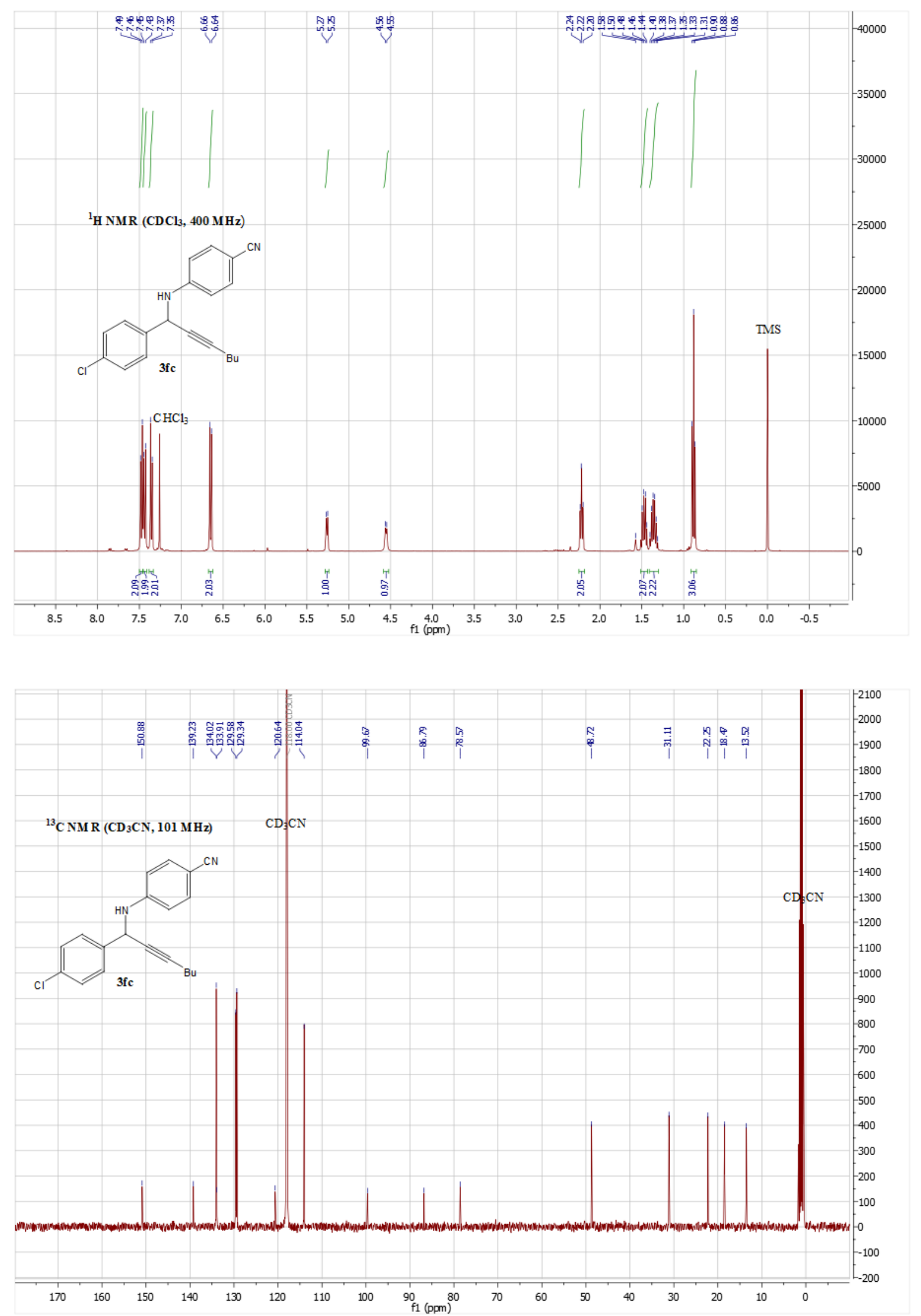

Figure S16. NMR spectra for $\mathbf{3 f c}$ 

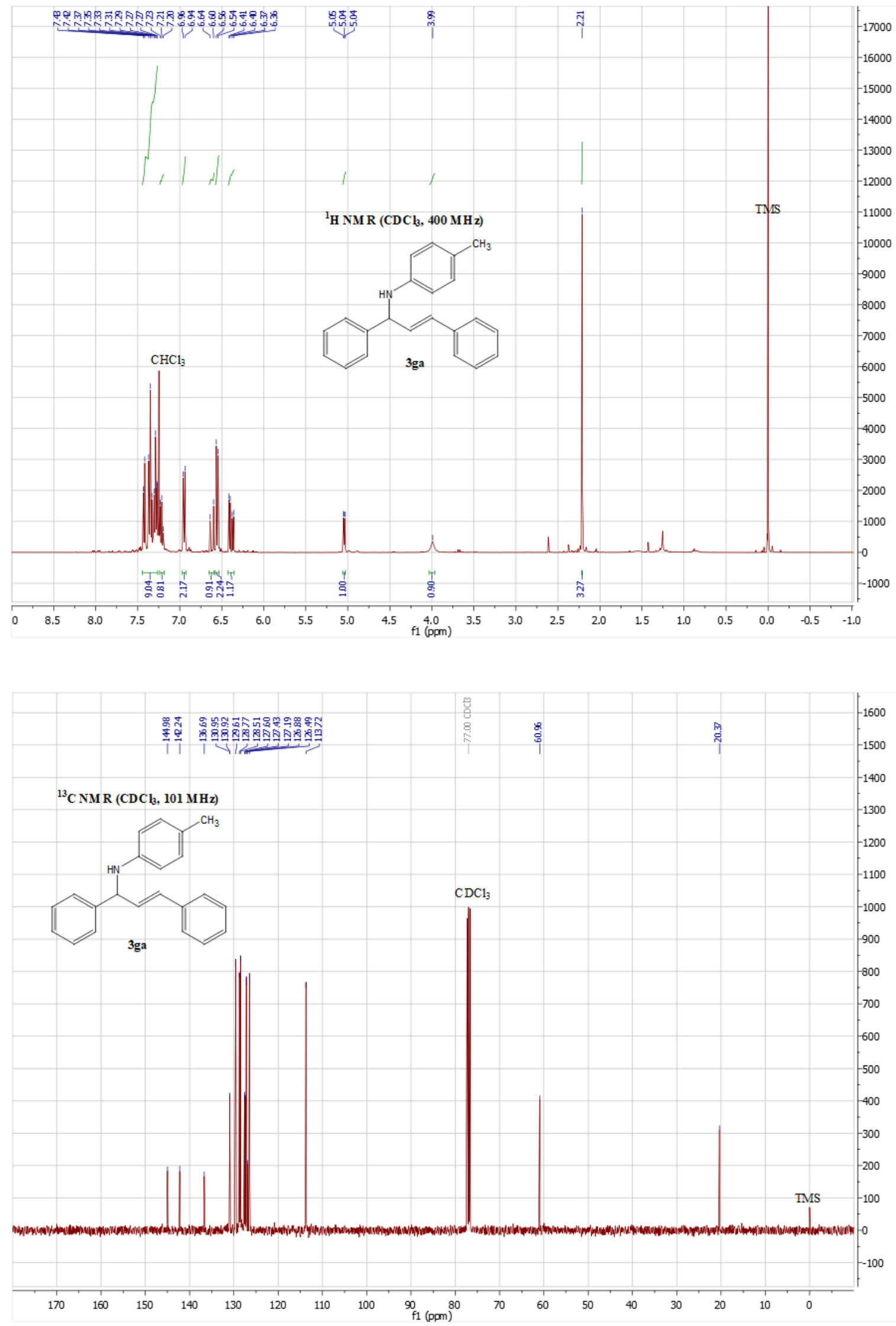

Figure S17. NMR spectra for 3ga 

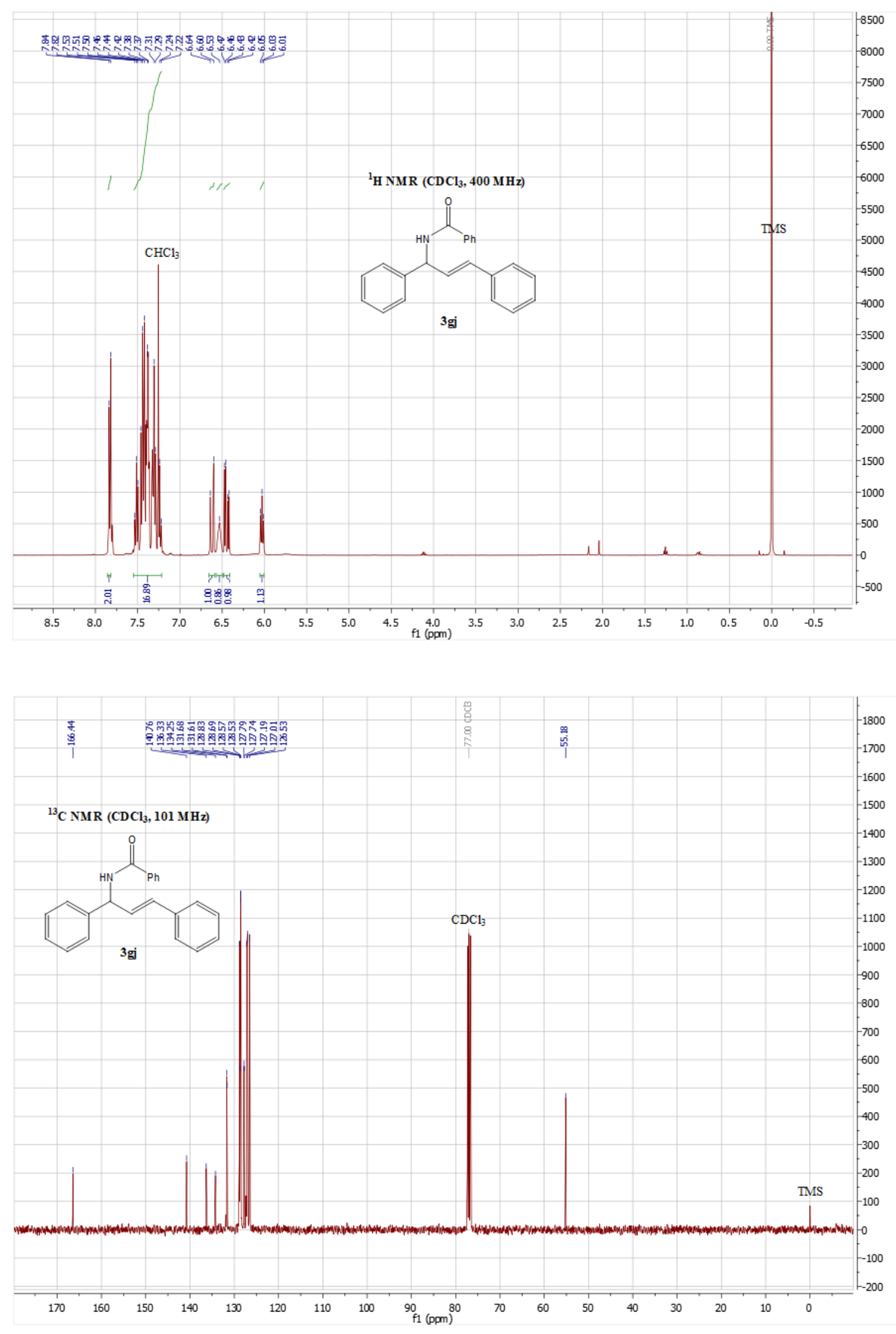

Figure S18. NMR spectra for 3gj 

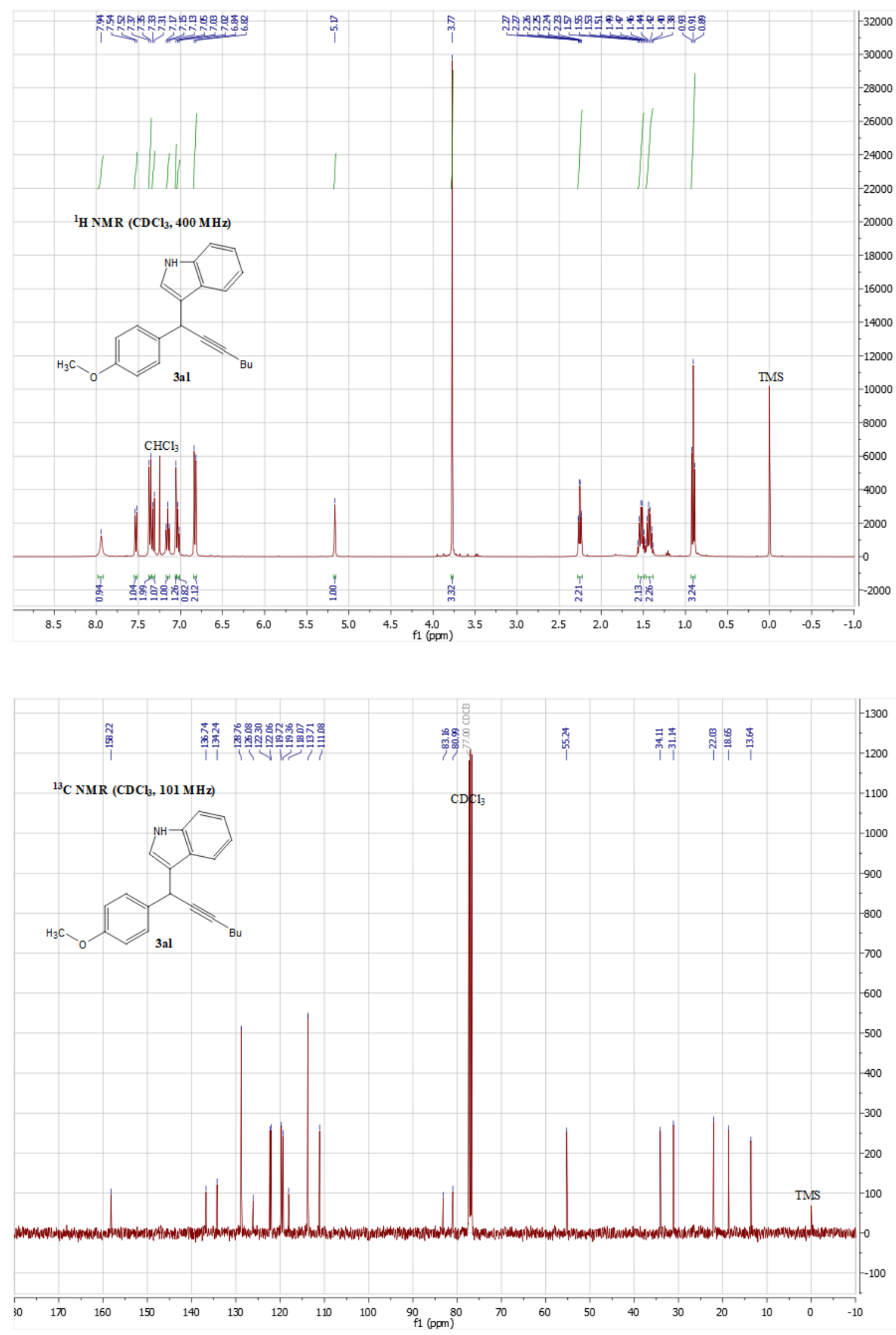

Figure S19. NMR spectra for $\mathbf{3 a l}$ 

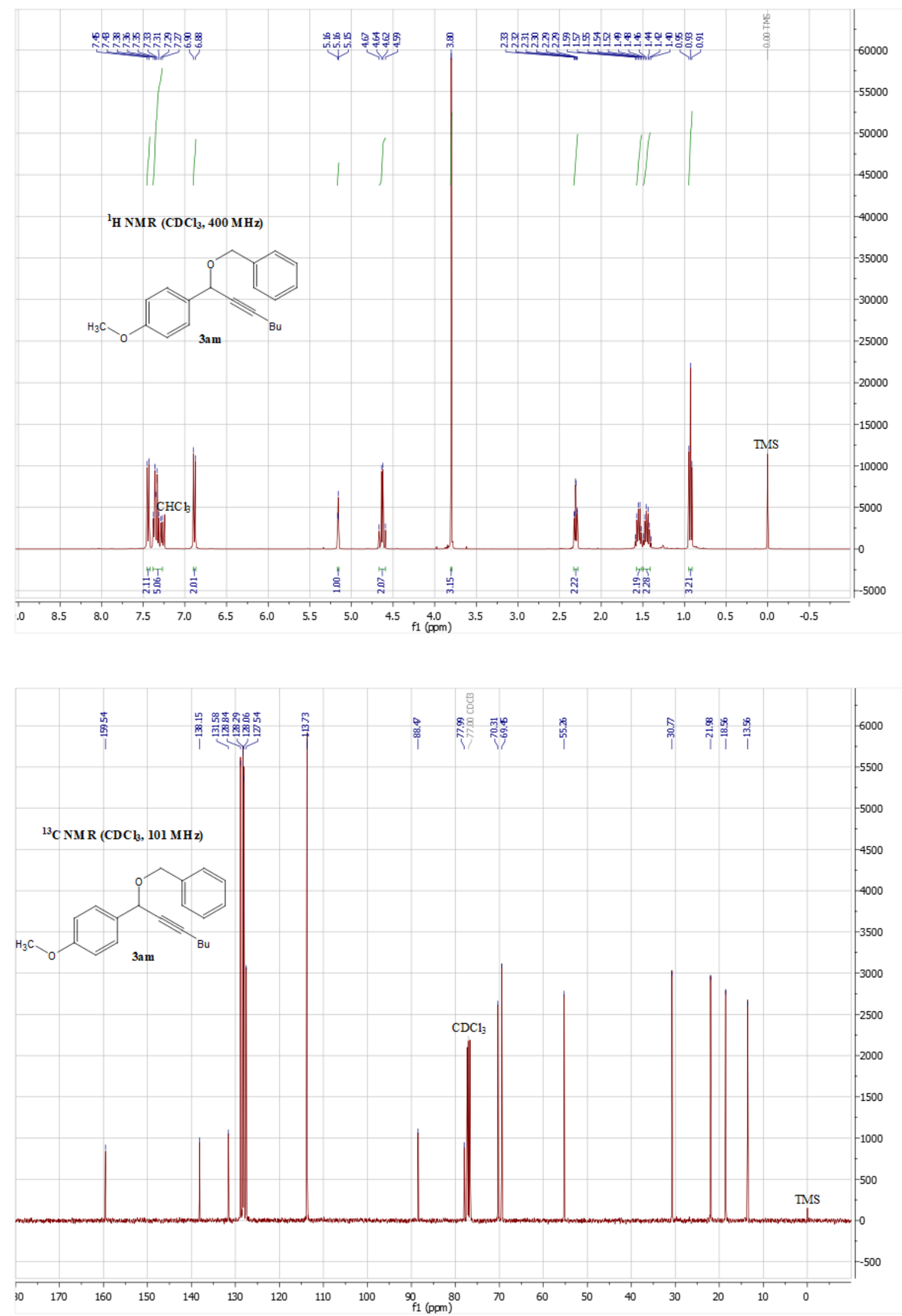

Figure S20. NMR spectra for 3am 

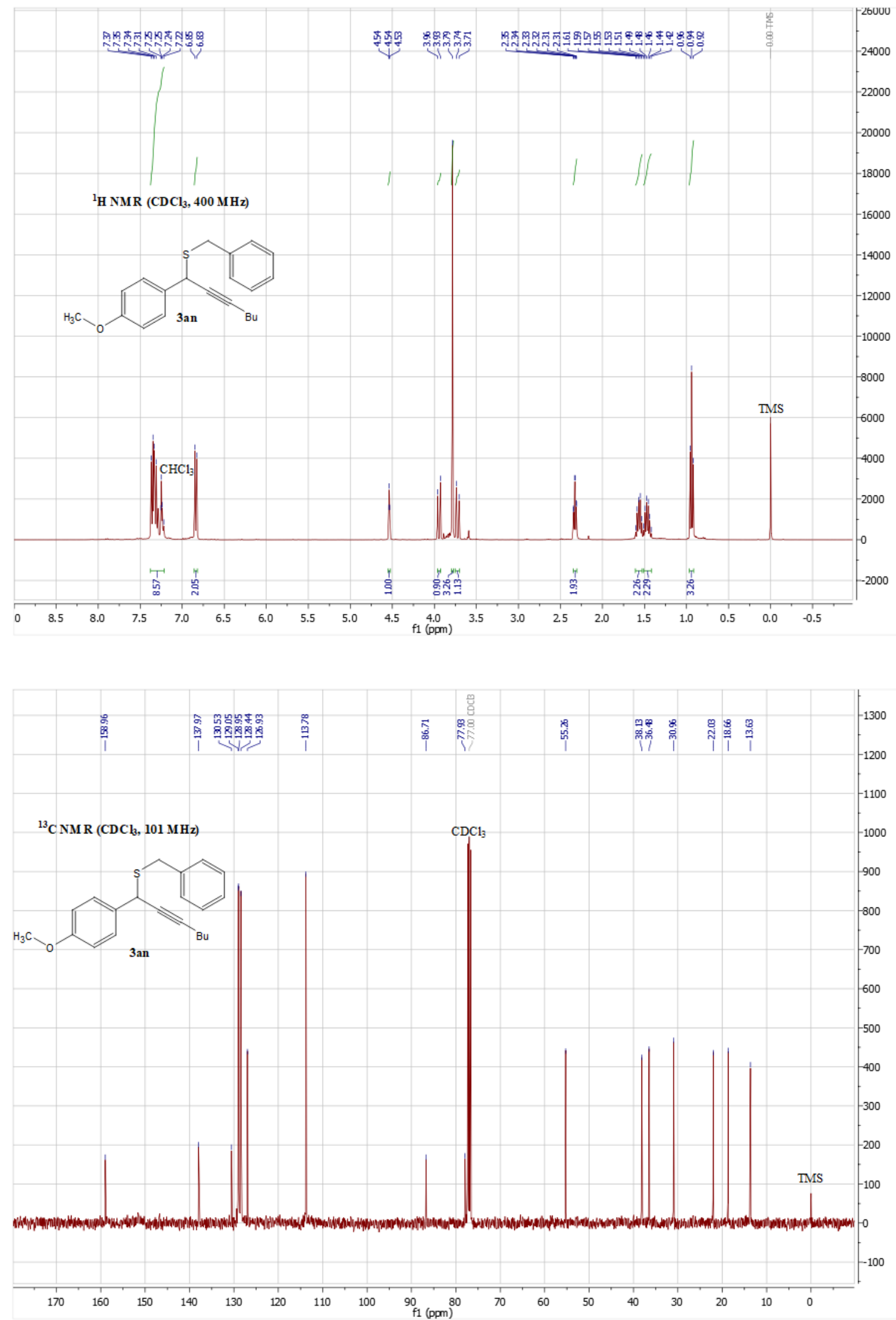

Figure S21. NMR spectra for 3an 

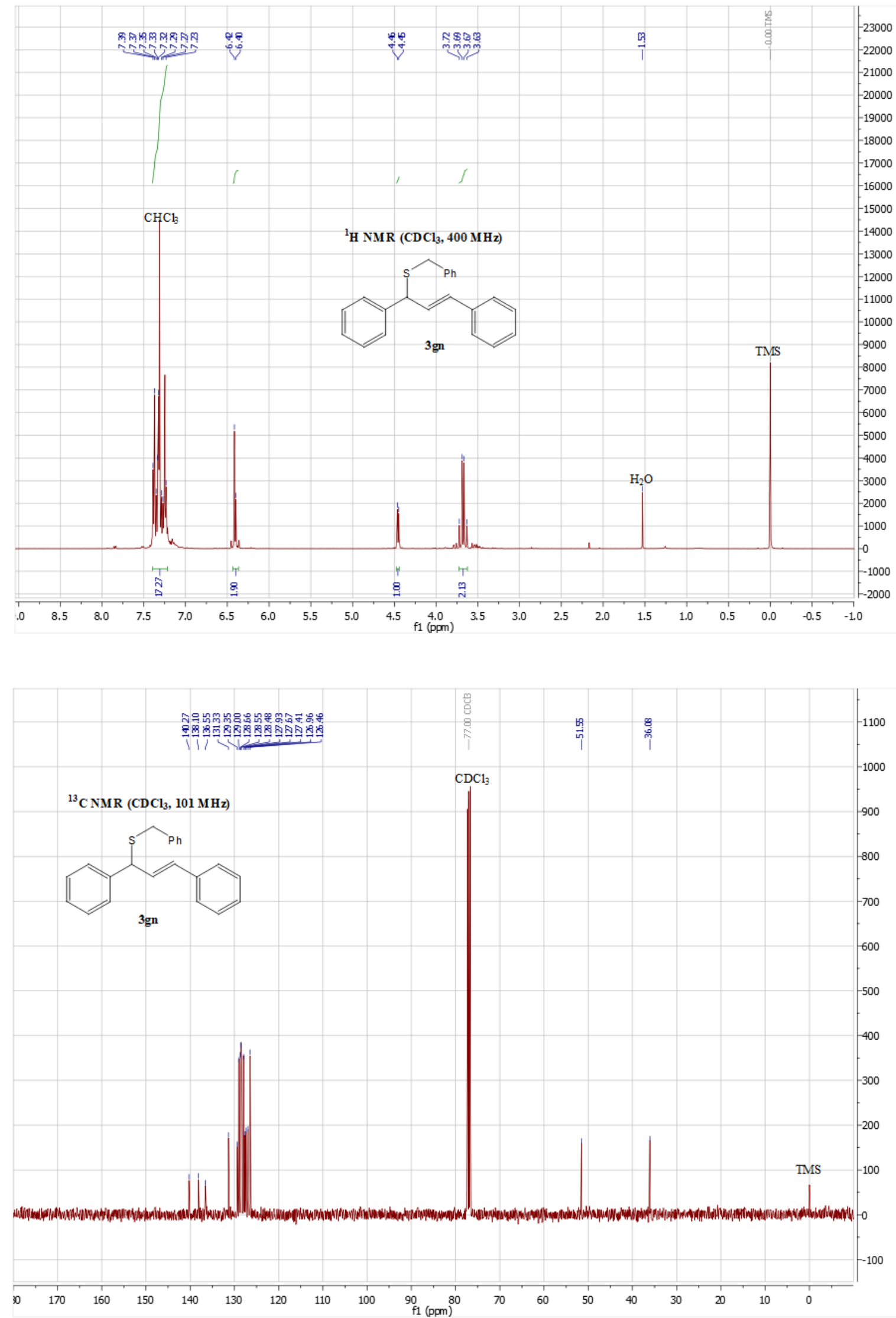

Figure S22. NMR spectra for 3gn 